University of Nebraska - Lincoln

DigitalCommons@University of Nebraska - Lincoln

Faculty Papers and Publications in Animal

Science

Animal Science Department

April 1990

\title{
ALTERNATIVE ANIMAL MODELS WITH MATERNAL EFFECTS AND FOSTER DAMS
}

L. Dale Van Vleck

University of Nebraska-Lincoln, dvan-vleck1@unl.edu

Follow this and additional works at: https://digitalcommons.unl.edu/animalscifacpub

Part of the Animal Sciences Commons

Van Vleck, L. Dale, "ALTERNATIVE ANIMAL MODELS WITH MATERNAL EFFECTS AND FOSTER DAMS"

(1990). Faculty Papers and Publications in Animal Science. 348.

https://digitalcommons.unl.edu/animalscifacpub/348

This Article is brought to you for free and open access by the Animal Science Department at DigitalCommons@University of Nebraska - Lincoln. It has been accepted for inclusion in Faculty Papers and Publications in Animal Science by an authorized administrator of DigitalCommons@University of Nebraska - Lincoln. 


\title{
ALTERNATIVE ANIMAL MODELS WITH MATERNAL EFFECTS AND FOSTER DAMS 1
}

\author{
L. D. Van Vleck ${ }^{2}$ \\ U.S. Department of Agriculture, Lincoln, NE 68583-0908
}

\begin{abstract}
Effects of foster dams can be included in genetic evaluations using animal models with maternal effects in several ways. The alternatives discussed involve minor changes in computing strategies from strategies used with reduced animal models that predict breeding values for direct and maternal effects. The easiest alternative is to assign foster dams to groups by breed and time period and add equations for fixed effects of breedperiod. Random and, assumed, independent effects of foster dams can be nested in breed-period groups. If foster dams do not repeat, then those effects can be absorbed into equations for other fixed effects, additive direct breeding value and breed-period effects by slightly modifying least squares contributions to coefficients of those equations. A third alternative for foster dams of the same breed is to add breeding values for foster dams for direct and maternal effects to solution vectors for breeding values. Equations are similar to those without foster dams, except that least squares contributions to coefficient matrix and right-hand sides are to equations for maternal breeding values and nongenetic maternal effects of foster dams rather than biological dams. Relationships and covariance between direct and maternal effects contribute mixedmodel coefficients to direct and maternal breeding value equations of biological dams. This alternative basically requires only larger solution vectors for direct and maternal breeding values to accommodate foster dams that might not be included. The fourth alternative includes a vector of maternal breeding values for foster dams of each breed of foster dams and would require using rules of Westell to calculate coefficients due to relationships and fixed maternal genetic groups within each breed of foster dam. These alternatives do not require much additional computational effort compared with full or reduced animal model equations when the transformation to predict breeding values is used with Westell's rules to calculate coefficients due to relationships and genetic group effects due to prior genetic selection.
\end{abstract}

(Key Words: Mixed Model Method, Genetic Models, Breeding Value, Embryo Transfer.)

J. Anim. Sci. 1990. 68:4026-4038

\section{Introduction}

Multiple ovulation and embryo transfer can lead to a female having many progeny, most of which will be gestated, born and raised by recipient females (referred to here as foster dams). Such progeny will have two mothers, the genetic or biological dam and the foster dam. For traits such as birth weight, early growth rate or newborn viability, the direct maternal influence is by the foster dam, which usually is unrelated to the progeny. An indirect maternal influence is due to the genetic relationship between the biological dam and the progeny and the genetic covariance between direct genetic effects and maternal genetic effects.

The animal model and its derivative, the reduced animal model, is widely used for genetic evaluation (Benyshek et al., 1988; Wiggans et al., 1988). Genetic groups assigned by selection

\footnotetext{
'Published as Paper No. 9030, Journal Ser., Nebraska Agric. Res. Div., Univ. of Nebraska, Lincoln.

${ }^{2}$ ARS, Roman L. Hruska U.S. Meat Anim. Res. Center, A218 Anim. Sci., Univ. of Nebraska, Lincoln 68583-0908. Received September 18, 1989.

Accepted April 12, 1990.
} 
paths and time period can be incorporated to account for selection not accounted for by numerator relationships and available records. Genetic groups for maternal effects can be made equivalent to genetic groups for direct effects (Van Vleck, 1990a) so that computations can be greatly simplified by the Q-P transformation (Quaas and Pollak, 1981) and by the absorption of base animals, which led Westell (1984) to discover simple rules for calculating the coefficients for the Q-P-W mixed model equations (Westell et al., 1984, 1988; Quaas, 1988). Rules for calculating coefficients for mixed-model equations similar to those derived by Quaas and Pollak (1980) for a reduced animal model can be found for a model with direct and maternal genetic groups by absorbing equations for direct and maternal breeding values of non-parents (Van Vleck, 1990b).

The purposes of this note are to discuss alternative ways of adjusting for effects of foster dams in an animal model and to show modifications needed to calculate the coefficients for the Q-PW equations after absorption of non-parent breeding values (the equivalent of the so-called reduced animal model).

\section{Methods}

The main considerations in accounting for effects of foster dams are to minimize bias in prediction of direct and maternal breeding values, to minimize variances of prediction errors, and to make the computing algorithm as efficient as possible. Computations that follow the pattern used for current genetic evaluation systems (L. Benyshek, 1989 and J. Brinks, 1989; personal communications) would be preferred.

A basic but perhaps unanswerable question is whether any procedure can account for the various ways foster dams are chosen or managed. If knowledge of the way foster dams are chosen or managed indicates that foster maternal effects cannot be fairly accounted for, then an obvious alternative is to exclude such records from genetic evaluations. The following alternatives, however, are for situations that can benefit from more or less complete methods of accounting for effects of foster dams.

The alternatives to be discussed are: 1) assign foster dams to breed-time period groups and include fixed breed-period effects in the model; 2) nest random foster dam effects within breedtime period groups but consider the foster dams to be unrelated (and a repeated foster dam as a different foster dam) and unrelated to animals included in the solution vectors for direct and maternal breeding values; 3 ) expand the solution vectors for direct and maternal breeding values of the primary breed to include foster dams of that breed not otherwise included. Genetic grouping would follow the same pattern as when foster dams are not included. Relationships among all animals including the foster dams would be utilized (alternative 3 is a subset of 4); and 4) assign genetic groups for foster dams separately by breed and utilize genetic relationships within breeds when foster dams are of many breeds.

Subsets of 1 and 2 would be situations with foster dams the same breed as the progeny. Options for 2, 3 and 4 include cases in which foster dams can be a foster dam more than once. The calculations are simpler when a foster dam is foster or biological dam only once. For situations in which some foster dams are repeat foster dams (not usually, but possibly for the same biological dam), the computing strategy may be different for the two types of foster dams if the type is known (foster dam only once vs more than once).

After this paper was submitted, Schaeffer and Kennedy (1989) discussed some of the same alternatives described here where surrogate dams were of a different breed than the biological dams without group effects to account for prior selection in the primary breed or the different breeds of surrogate dams.

An important consideration that will not be discussed here is whether adjustments for effects such as age of dam are the same for all breed-time period groups. A similar consideration that also will not be discussed is whether phenotypic or maternal variances depend on the breed-time period group of the foster dam (Schaeffer and Kennedy, 1989).

The single-trait model to be discussed includes direct additive genetic effects, maternal additive genetic effects, one set of fixed effects for illustration, and nongenetic maternal effects of the dams (for dams with more than one offspring). 
The mixed-model equations will be assumed to be those after application of the Q-P transformation and absorption of foundation animals (Quaas and Pollak, 1981; Westell, 1984; Westell, et al., 1984, 1988; Quaas, 1988). The model will include genetic group effects for both direct and maternal effects. The vectors of breeding values will contain the direct and maternal genetic effects for the same animals, with genetic groups for maternal effects assigned similarly to those for direct effects, i.e., by assigning both parents of the most recent female ancestor with progeny, but without a record, to the genetic group to which she would have been assigned if maternal effects were ignored (Van Vleck, 1990a, b). The resulting equations will be referred to as the Q-P-W equations, where:

$\beta$ will represent, for illustration, a vector of fixed effects of which one is associated with each record,

$a^{*}$ will represent the vector of breeding values for direct genetic effects (deviation vector, a, plus the appropriate functions of genetic group effects, $\mathrm{Qg}_{\mathrm{a}}$ ) with the vector of genetic group effects, $g_{a}$, at the bottom of the vector for convenience,

$\mathrm{m}^{*}$ will represent the corresponding vector of breeding values for maternal genetic effects and maternal genetic group effects, $g_{m}$,

$p$ will represent the vector of permanent environmental plus non-additive genetic maternal effects contributed by dams to their progeny records, and

e will represent the vector of residual (environmental) effects peculiar to single records that are not accounted for by other parts of the model.

Animals with records and those without records but having more than one collateral descendant with records as well as dams with progeny but without records will be included in a and $\mathrm{m}$ and thus in $\mathrm{a}^{*}$ and $\mathrm{m}^{*}$ (Henderson, 1977). Only nongenetic effects of animals in $\mathrm{m}$ with progeny (biological or foster) need to be included in $\mathrm{p}$.

Then $\mathrm{V}\left(\begin{array}{c}\mathrm{a} \\ \mathrm{m} \\ \mathrm{p} \\ \mathrm{e}\end{array}\right)$ ( $\left(\begin{array}{llll}\mathrm{A} \sigma_{\mathrm{a}}^{2} & \mathrm{~A} \sigma_{\mathrm{am}} & 0 & 0 \\ \mathrm{~A} \sigma_{\mathrm{am}} & \mathrm{A} \sigma_{\mathrm{m}}^{2} & 0 & 0 \\ 0 & 0 & \mathrm{I}_{\mathrm{p}} \sigma_{\mathrm{p}}^{2} & \\ 0 & 0 & 0 & \mathrm{I}_{\mathrm{e}} \sigma_{\mathrm{e}}^{2}\end{array}\right)$

where $I_{p}$ has order the length of $p$,

$\mathrm{I}_{\mathrm{e}}$ has order the number of records, and

$A$ is the numerator relationship matrix for animals contained in a (calculated including foundation animals). Direct product properties are utilized to simplify writing the Q-P-W equations, where

$\mathrm{V}\left(\begin{array}{c}\mathrm{a} \\ \mathrm{m}\end{array}\right)=\mathrm{G}_{\mathrm{o}} * \mathrm{~A}$ with $\mathrm{G}_{\mathrm{o}}=\left(\begin{array}{cc}\sigma_{\mathrm{a}}^{2} & \sigma_{\mathrm{am}} \\ \sigma_{\mathrm{am}} & \sigma_{\mathrm{m}}^{2}\end{array}\right)$.

Elements associated with the Q-P-W equations are a function of $\sigma_{\mathrm{e}}^{2} \mathrm{G}_{\mathrm{o}}^{-1}=\left(\begin{array}{ll}\alpha & \lambda \\ \lambda & \gamma\end{array}\right)$.

Similarly, let $\delta \square \sigma_{\mathrm{e}}^{2} / \sigma_{\mathrm{p}}^{2}$.

In the absorption of equations for non-parents (Van Vleck, 1990b), when deriving the equivalent of the equations for a reduced animal model with direct and maternal group effects, block absorption of the two equations for direct and maternal breeding values of each non-parent requires $\left(\begin{array}{ll}\alpha^{*} & \lambda^{*} \\ \lambda^{*} & \gamma^{*}\end{array}\right)=\left(\begin{array}{cc}1+\mathrm{D} \alpha & \mathrm{D} \lambda \\ \mathrm{D} \lambda & \mathrm{D} \gamma\end{array}\right)^{-1}$ 
where D

arises for each non-parent from the rules of Westell (Westell, 1984; Westell et al., 1984, 1988; Quaas, 1988):

$\mathrm{D}=2$, if both parents are in a and the animal is not inbred (if inbred, then $\mathrm{D}$ is calculated as described by Quaas $(1976,1988)$;

$\mathrm{D} \square \mathrm{4} / 3$, if one parent is in a and a genetic group is a proxy for the other parent; and

$\mathrm{D} \square$ 1, if neither parent is in a and genetic groups are proxies for both parents.

Terms that arise in the absorption (Van Vleck, 1990b) are:

$$
\begin{aligned}
& \phi_{0}=1-\alpha^{*} \\
& \phi_{1}=\mathrm{D}\left(\alpha \alpha^{*}+\lambda \lambda^{*}\right) / 2=\phi_{0} / 2 \\
& \phi_{2}=\mathrm{D}\left(\lambda \alpha^{*}+\gamma \lambda^{*}\right) / 2=0 \\
& \phi_{3}=\mathrm{D}^{2}\left(\alpha \alpha \alpha^{*}+2 \alpha \lambda \lambda^{*}+\lambda \lambda \gamma^{*}\right) / 4=\mathrm{D} \alpha / 4-\phi_{0} / 4 \\
& \phi_{4} \text { ㅁ } \mathrm{D}^{2}\left(\alpha \lambda \alpha^{*}+\lambda \lambda \lambda^{*}+\alpha \gamma \lambda^{*}+\lambda \gamma \gamma^{*}\right) / 4 \text { ㅁ } \mathrm{D} \lambda / 4 \\
& \phi_{5}=\mathrm{D}^{2}\left(\lambda \lambda \alpha^{*}+2 \lambda \gamma \lambda^{*}+\gamma \gamma \gamma^{*}\right) / 4=\mathrm{D} \gamma / 4
\end{aligned}
$$

Minor modifications of these terms will result if foster dams are considered either as fixed effects or if nongenetic maternal effects are included when the biological dam furnishes maternal effects but are not included for foster dams.

In this development for a single trait, the coefficient matrix for the mixed-model equations and the right-hand-side vector are assumed to be multiplied by $\sigma_{e}^{2}$. With foster dams, the phenotypic variance is different from that when the biological dam provides the postnatal maternal function, even if the foster dam is the same breed and is included in the a and $m$ vectors. The phenotypic variance, $\sigma_{\mathrm{y}}^{2}$, usually is partitioned as $\sigma_{\mathrm{y}}^{2}=\sigma_{\mathrm{a}}^{2}+\sigma_{\mathrm{m}}^{2}+2 \mathrm{a}_{\mathrm{PD}} \sigma_{\mathrm{am}}+\sigma_{\mathrm{p}}^{2}+\sigma_{\mathrm{e}}^{2}$, where a dam relationship. For the no inbreeding situation, $\mathrm{a}_{\mathrm{PD}}=1 / 2$ and $\boldsymbol{\sigma}_{\mathrm{y}}^{2}=\boldsymbol{\sigma}_{\mathrm{a}}^{2}+\sigma_{\mathrm{m}}^{2}+\boldsymbol{\sigma}_{\mathrm{am}}+\boldsymbol{\sigma}_{\mathrm{p}}^{2}+\boldsymbol{\sigma}_{\mathrm{e}}^{2}$. If the foster dam is unrelated to the progeny, $\sigma_{\mathrm{y}}^{2}=\sigma_{\mathrm{a}}^{2}+\sigma_{\mathrm{m}}^{2}+\sigma_{\mathrm{p}}^{2}+\sigma_{\mathrm{e}}^{2}$. Residual variances, however, are the same for both cases.

If the fixed model for foster dam effects is used, then the question arises of what is the residual variance for records made with a foster dam? If the assumption can be made that the fixed effect accounts for all maternal effects, then the residual variance for records of progeny with foster and biological dams is the same. On the other hand, if the more reasonable argument is made that the fixed effect simply accounts for the mean effect of the foster dam group, then the variation of maternal effects within breed-time group would still exist. Ignoring that, variation changes the residual variance to $\sigma_{\mathrm{e}}^{2 *}=\sigma_{\mathrm{m}}^{2}+\sigma_{\mathrm{e}}^{2}$ or $\sigma_{\mathrm{e}}^{2 *}=\sigma_{\mathrm{m}}^{2}+\sigma_{\mathrm{p}}^{2}+\sigma_{\mathrm{e}}^{2}$. The appropriate multiplier for the least squares contributions to the mixed-model equations for records of progeny of foster dams would be $\mathrm{r} \square \sigma_{\mathrm{e}}^{2} / \sigma_{\mathrm{e}}^{2 *}$ rather than $\sigma_{\mathrm{e}}^{2} / \sigma_{\mathrm{e}}^{2}=1$.

If the model for records of progeny with the biological dam also furnishing the maternal effects includes $\mathrm{p}$ but the foster dams do not repeat, and $\mathrm{p}$ is not included in the model for progeny of foster dams, then the residual variance is $\sigma_{\mathrm{e}}^{2 *}=\sigma_{\mathrm{p}}^{2}+\sigma_{\mathrm{e}}^{2}$ when maternal effects of foster dams are considered random with $\mathrm{r}=\sigma_{\mathrm{e}}^{2} / \sigma_{\mathrm{e}}^{2} *$.

In such cases, the absorption of equations for a non-parent will involve:

$$
\left(\begin{array}{cc}
\mathrm{r}+\mathrm{D} \alpha & \mathrm{D} \lambda \\
\mathrm{D} \lambda & \mathrm{D} \gamma
\end{array}\right)^{-1}=\left(\begin{array}{ll}
\alpha^{+} & \lambda^{+} \\
\lambda^{+} & \gamma^{+}
\end{array}\right)
$$

with corresponding $\phi_{0}^{+}, \phi_{1}^{+}, \phi_{2}^{+}=0, \phi_{3}^{+}, \phi_{4}^{+}=\mathrm{D} \lambda / 4$ and $\phi_{5}^{+}=\mathrm{D} \gamma / 4$. Note that $\phi_{1}^{+}=\phi_{0}^{+} / 2$ and $\phi_{3}^{+} \square$ $\mathrm{D} \alpha / 4-\phi_{0}^{+} / 4$ so that $\mathrm{D} \alpha / 4-\phi_{3}^{+}=\phi_{0}^{+} / 4$.

Most data sets containing data with foster dams will contain a mixture of records from progeny with the biological dam providing maternal effects and from progeny with foster dams. Thus, the options that follow will show the changes that are made for records of progeny with foster dams from the way coefficients and right-hand sides are calculated for progeny with biological dams. The basis will be the Q-P-W equations described by Van Vleck (1990a) and the Q-P-W equations after the direct and maternal equations for non-parents are absorbed, the RAM-Q-P-W equations (Van Vleck, 1990b). For animals without a foster dam, the contributions to the coefficient matrix and right-hand sides of the RAM-Q-P-W equations are given by Van Vleck 
(1990b; table 2 for non-parents, table 3 for parents with records and table 4 for parents without records).

\section{Fixed Breed-Time Periods to Represent Foster Dams}

The derivation of the rules for the coefficient matrix and right- hand sides equivalent to those for RAM-Q-P-W can be illustrated by following Table 1 through Table 2. Table 1 shows the modification of Table 1 of Van Vleck (1990b) for fixed breed-period effects to represent fosterdam effects. The ones contributing to the least squares portions of the coefficients are replaced by $\mathrm{r} \square \sigma_{\mathrm{e}}^{2} / \sigma_{\mathrm{e}}^{2 *}$, with $\sigma_{\mathrm{e}}^{2 *}$ being appropriate to the residual for records with a fixed breed-period group, $f$, representing the foster dam. The fixed breed-period group effect, $F_{f}$, appears instead of the permanent environmental effect, $p_{j}$, which would have been contributed by the biological dam. $A$ least squares $r$ is not assigned to the maternal genetic effect of the biological dam. If nonparents are not absorbed, coefficients for the maternal genetic effect of the biological dam arise through the relationship between progeny and mother and the covariance structure of direct and maternal genetic effects, exactly the same as for the maternal genetic effect of the sire. The equations for maternal genetic effects for the sire and dam will drop out if the fostered progeny is a non-parent and its direct and maternal equations are absorbed. The progeny record, $\mathrm{y}_{\mathrm{i}}$, weighted by $r$ contributes to three right-hand sides corresponding to $\beta_{k}, a_{i}^{*}$ and $F_{\mathrm{f}}$. Note that no contribution goes to the right-hand side for the equation for the maternal effect of the biological dam (or biological sire), which corresponds to the lack of least squares r's on the left-hand sides for maternal genetic effects of the biological parents. Table 2 shows the contributions to the coefficient matrix and right-hand sides if the non-parent, direct and maternal, equations are absorbed. The absorption involves $\mathrm{r}$ and the $\phi^{+}$rather than the $\phi$. The coefficients contributing to the equations for the sire and dam maternal effects algebraically simplify to zero and are not shown in Table 2.

For completeness, Table 3 shows the coefficients and right-hand sides associated with a record of a parent that had a foster dam.

Thus, as can be seen from Tables 2 and 3, essentially the same steps for forming the RAM-Q$P$-W equations can be followed when foster dam effects are accounted for by fixed breed-period effects (or other assignments) as for the usual RAM-Q-P-W case. Additional equations will need to be formed for whatever number of foster dam groups are assigned. Because breed-period

TABLE I. CONTRIBUTIONS TO COEFFICIENT MATRIX AND RIGHT-HAND-SIDE

VECTOR ASSOCIATED WITH A NON-PARENT, i, THAT HAS SIRE OR PROXY, s, BIOLOGICAL DAM, j, FOSTER-DAM GROUP, $f$, AND RECORD, $y_{i}$, CONTAINING OTHER FIXED EFFECT, $\beta_{k}$ ab

\begin{tabular}{|c|c|c|c|c|c|c|c|c|c|}
\hline \multirow{2}{*}{$\begin{array}{l}\text { Equation } \\
\text { (row) }\end{array}$} & \multicolumn{8}{|c|}{ Column } & \multirow{2}{*}{$\begin{array}{l}\text { Right-hand } \\
\text { side }\end{array}$} \\
\hline & $a_{1}^{*}$ & $\mathrm{~m}_{\mathrm{i}}^{*}$ & $\beta_{\mathbf{k}}$ & $F_{r}$ & $a_{\mathrm{s}}^{*}$ & $\mathrm{~m}_{\mathrm{s}}^{*}$ & $a_{j}^{*}$ & $\mathrm{~m}_{\mathrm{j}}^{*}$ & \\
\hline $\mathrm{a}_{\mathrm{i}}^{*}$ & $\mathrm{r}+\mathrm{D} \alpha$ & $\mathrm{D} \lambda$ & $r$ & $\mathrm{r}$ & $-\mathrm{D} \alpha / 2$ & $-\mathrm{D} \lambda / 2$ & $-\mathrm{D} \alpha / 2$ & $-\mathrm{D} \lambda / 2$ & $r y_{i}$ \\
\hline $\mathrm{m}_{\mathrm{i}}^{*}$ & $D \lambda$ & $\mathrm{D} \gamma$ & 0 & 0 & $-\mathrm{D} \lambda / 2$ & $-D_{\gamma / 2}$ & $-\mathrm{D} \lambda / \mathrm{a}$ & $-\mathrm{D} \gamma / 2$ & 0 \\
\hline$\beta_{k}$ & $r$ & 0 & r & I & 0 & 0 & 0 & 0 & $r y_{i}$ \\
\hline$F_{f}$ & $r$ & 0 & $r$ & $r$ & 0 & 0 & 0 & 0 & $r y_{i}$ \\
\hline$a_{s}^{*}$ & $-\mathrm{D} \alpha / 2$ & $-\mathrm{D} \lambda / 2$ & 0 & 0 & $\mathrm{D} \alpha / 4$ & $\mathrm{D} \lambda / 4$ & $\mathrm{D} \alpha / 4$ & $\mathrm{D} \lambda / 4$ & 0 \\
\hline $\mathrm{m}_{\mathrm{s}}^{*}$ & $-D \times / 2$ & $-D \gamma / 2$ & 0 & 0 & $D \lambda / 4$ & $\mathrm{D} \gamma / 4$ & $\mathrm{D} \lambda / 4$ & $\mathrm{D} \gamma / 4$ & 0 \\
\hline$a_{j}^{*}$ & $-\mathrm{D} \alpha / 2$ & $-\mathrm{D} X / 2$ & 0 & 0 & $D \alpha / 4$ & $\mathrm{D} \lambda / 4$ & $\mathrm{D} \alpha / 4$ & $\mathrm{D} \lambda / 4$ & 0 \\
\hline $\mathrm{m}_{\mathrm{j}}^{*}$ & $-\mathrm{D} \lambda / 2$ & $-\mathrm{D} \gamma / 2$ & 0 & 0 & $D \lambda / 4$ & $\mathrm{D} \gamma / 4$ & $\mathrm{D} \lambda / 4$ & $\mathrm{D} \gamma / 4$ & 0 \\
\hline
\end{tabular}

$\mathrm{a}_{\mathrm{r}}=\sigma_{\mathrm{e}}^{2} / \sigma_{\mathrm{e}}^{2} *$ with $\sigma_{\mathrm{e}}^{2 *}=\sigma_{\mathrm{m}}^{2}+\sigma_{\mathrm{p}}^{2}+\sigma_{\mathrm{e}}^{2}$ if nongenetic maternal effects are included in the model for progeny with biological dams but not for progeny with foster dams and $\sigma_{\mathrm{e}}^{2}=a_{\mathrm{m}}^{2}+\sigma_{\mathrm{e}}^{2}$ if nongenetic effects of foster and biological dams are included in the model.

bRules for calculation of $W$ accommodate $a^{*}$ and $g_{a}\left(m^{*}\right.$ and $\left.g_{m}\right)$ simultaneously. Therefore, the $g_{a}\left(g_{m}\right)$ vector is assumed to be part of the $a^{*}\left(\mathrm{~m}^{*}\right)$ vector. 
TABLE 2. ELEMENTS, AFTER SIMPLIFICATION, CONTRIBUTED TO COEFFICIENT MATRIX AND RIGHT-HAND-SIDE VECTOR RESULTING FROM ABSORPTION OF EQUATIONS FOR NON-PARENT, i, THAT HAS SIRE (OR PROXY), s, BIOLOGICAL DAM, j, FOSTER DAM IN FIXED GROUP, f, AND RECORD, $y_{i}$, CONTAINING FIXED EFFECT, $\beta_{k}$

\begin{tabular}{cccccc}
\hline & \multicolumn{3}{c}{ Column } & \\
\cline { 2 - 5 } $\begin{array}{c}\text { Equation } \\
\text { (row) }\end{array}$ & $\beta_{\mathrm{k}}$ & $\mathrm{F}_{\mathrm{f}}$ & $\mathrm{a}_{\mathrm{s}}^{*}$ & $\mathrm{a}_{\mathrm{j}}^{*}$ & $\begin{array}{c}\text { Right-hand } \\
\text { side }\end{array}$ \\
\hline$\beta_{\mathrm{k}}$ & $\phi_{0}^{+}$ & $\phi_{0}^{+}$ & $\phi_{0}^{+} / 2$ & $\phi_{0}^{+} / 2$ & $\phi_{0}^{+} \mathrm{y}_{\mathrm{i}}$ \\
$\mathrm{F}_{\mathrm{f}}$ & Symmetric & $\phi_{0}^{+}$ & $\phi_{0}^{+} / 2$ & $\phi_{0}^{+} / 2$ & $\phi_{0}^{+} \mathrm{y}_{\mathrm{i}}$ \\
$\mathrm{a}_{5}^{*}$ & & $\phi_{0}^{+} / 4$ & $\phi_{0}^{+} / 4$ & $.5 \phi_{0}^{+} \mathrm{y}_{\mathrm{i}}$ \\
$\mathrm{a}_{\mathrm{j}}^{*}$ & & & & $\phi_{0}^{+} / 4$ & $.5 \phi_{0}^{*} \mathrm{y}_{\mathrm{i}}$ \\
\hline
\end{tabular}

TABLE 3. ELEMENTS OF COEFFICIENT MATRIX AND RIGHT-HAND-SIDE VECTOR CONTRIBUTED BY A RECORD, $y_{i}$, OF A PARENT, i, WITH SIRE (OR PROXY), s, WITH BIOLOGICAL DAM, j, AND FOSTER DAM IN FIXED GROUP, $\mathrm{f}^{\mathrm{a}}$

\begin{tabular}{|c|c|c|c|c|c|c|c|c|c|}
\hline \multirow{2}{*}{$\begin{array}{l}\text { Equation } \\
\text { (row) }\end{array}$} & \multicolumn{8}{|c|}{ Column } & \multirow{2}{*}{$\begin{array}{l}\text { Right-hand } \\
\text { side }\end{array}$} \\
\hline & $\beta_{\mathrm{k}}$ & $F_{f}$ & $a_{i}^{*}$ & $\mathrm{~m}_{\mathrm{i}}^{*}$ & $a_{s}^{*}$ & $\mathrm{~m}_{\mathrm{s}}^{*}$ & $a_{j}^{*}$ & $\mathrm{~m}_{j}^{*}$ & \\
\hline$\beta_{\mathrm{k}}$ & $r$ & I & $r$ & & & & & & $\tau y_{i}$ \\
\hline$F_{f}$ & $r$ & $r$ & $\Gamma$ & & & & & & $r y_{j}$ \\
\hline$a_{i}^{*}$ & $\mathrm{r}$ & $r$ & $\mathrm{r}+\mathrm{D} \alpha$ & $\mathrm{D} \lambda$ & $-\mathrm{D} \alpha / 2$ & $-\mathbf{D} \lambda / 2$ & $-\mathrm{D} \alpha / 2$ & $-\mathrm{D} \lambda / 2$ & $r y_{i}$ \\
\hline $\mathrm{m}_{\mathrm{i}}^{*}$ & & & $\mathrm{D} \lambda$ & $\mathrm{D} \gamma$ & $-\mathrm{D} \lambda / 2$ & $-\mathrm{D} \gamma / 2$ & $-\mathrm{D} \lambda / 2$ & D $\gamma / 2$ & 0 \\
\hline$a_{s}^{*}$ & & & $-\mathrm{D} \alpha / 2$ & $-\mathrm{D} \lambda / 2$ & $\mathrm{D} \alpha / 4$ & $\mathrm{D} N / 4$ & $\mathrm{D} \alpha / 4$ & $\mathrm{D} \lambda / 4$ & 0 \\
\hline $\mathrm{m}_{\mathrm{s}}^{*}$ & & & $-\mathrm{D} \lambda / 2$ & $-\mathrm{D} \gamma / 2$ & $\mathrm{D} \lambda / 4$ & $\mathrm{D}_{\gamma / 4} 4$ & $\mathrm{D} \lambda / 4$ & $\mathrm{D} \gamma / 4$ & 0 \\
\hline$a_{j}^{*}$ & & & $-D \alpha / 2$ & $-D \lambda / 2$ & $D \alpha / 4$ & $D \lambda / 4$ & $\mathrm{D} \alpha / 4$ & $\mathrm{D} \lambda / 4$ & 0 \\
\hline $\mathrm{m}_{j}^{*}$ & & & $-\mathrm{D} \lambda / 2$ & $-D_{\gamma} / 2$ & $\mathrm{D} \lambda / 4$ & $\mathrm{D} \gamma / 4$ & $\mathrm{D} \lambda / 4$ & $\mathrm{D} \gamma / 4$ & 0 \\
\hline
\end{tabular}

$a_{\mathrm{r}}=\sigma_{\mathrm{e}}^{2} / \sigma_{\mathrm{e}}^{2} *$ with $\sigma_{\mathrm{e}}^{2} *=\sigma_{\mathrm{m}}^{2}+\sigma_{\mathrm{p}}^{2}+\sigma_{\mathrm{e}}^{2}$ or with $\sigma_{\mathrm{e}}^{2} *=\sigma_{\mathrm{m}}^{2}+\sigma_{\mathrm{e}}^{2}$ as for Table 1 .

effects are treated as fixed effects, no ratio of variances is added to the diagonal coefficients of those equations before solving.

\section{Foster Dams Considered as Random, Not Related, and Nested Within Fixed Breed-Period Groups}

A model more in accordance with mixed models is one that nests foster dams within fixed breed-period groups and for computational convenience ignores relationships among the foster dams and treats a female that rears more than one foster progeny as a separate foster dam for each fostered progeny. In this case, the steps are only slightly more complicated than when fixed breedperiod effects account for foster dam effects. The modifications result from the algebraic absorption of the nested foster dam effects into the other equations.

The coefficients associated with absorption of nested foster dam effects are calculated easily. Only additions to the coefficient matrix associated with entries caused by the least squares portion of the mixed model equations and right-hand sides are affected. The least squares contributions with $\zeta=\sigma_{\mathrm{e}}^{2} /\left(\sigma_{\mathrm{m}}^{2}+\sigma_{\mathrm{p}}^{2}\right)$ added to the diagonal of the equation associated with the nested foster dam effect, $b_{k f}$, of animal $i$, would appear as:

$$
\left(\begin{array}{cccc}
r+\zeta & r & r & r \\
r & r & r & r \\
r & r & r & r \\
r & r & r & r
\end{array}\right)\left(\begin{array}{c}
\hat{b}_{k f} \\
\hat{F}_{f} \\
\hat{a}_{i}^{*} \\
\hat{\beta}_{i}
\end{array}\right)=\left(\begin{array}{c}
r y_{i} \\
r y_{i} \\
r y_{i} \\
r y_{i}
\end{array}\right)
$$


Because the pretense is that the foster dam does not repeat as a foster dam, the nested foster dam effect can be absorbed easily into the equations for foster group effect $\left(\hat{\mathrm{F}}_{\mathrm{k}}\right)$, animal's breeding value $\left(\mathrm{a}_{\mathrm{j}}^{*}\right)$, and fixed effect $\left(\hat{\beta}_{0}\right)$ for parent records or further absorbed for non-parent records. The contributions to the three right-hand sides for parent records would be $\left.r^{*}\right) y_{i,}$, where $r^{*}=r \zeta /(r+\zeta)$ and would be $r^{*}$ to the three by three block of coefficients for $\hat{\mathbf{F}}_{k}, \hat{a}_{i}^{*}$ and $\hat{\beta}$ l rather than the $r$ shown in Tables 1 and 3. Further algebraic absorption for non-parent records leads to simple modifications of Tables 1 and 2. Simply replace $r$ with $r^{*}$ and proceed as before from Table 1 to arrive at rules comparable to Table 2 . Note that the absorptions would involve

$$
\left(\begin{array}{ll}
\mathrm{r}^{*}+\mathrm{D} \alpha & \mathrm{D} \lambda \\
\mathrm{D} \lambda & \mathrm{D} \gamma
\end{array}\right)^{-1}
$$

and corresponding changes in the $\phi$ 's (i.e., the formulas involve $r^{*}$ rather than $r$ ). Thus, again these calculations are not much more difficult to implement than for the usual RAM-Q-P-W equations.

\section{Foster Dam of Same Breed with Relationships Considered}

Obviously, the previous two alternatives also can be used for foster dams of the same breed as their foster progeny. In fact, good reasons might be made for either way of accounting for the foster dam effect. If management for foster dams of the same breed is not different, then the relationships to the progeny and other members of the breed logically should be considered. Predictions of direct and maternal breeding values also might be wanted for the foster dams. In that case, the foster dams would be included in the vectors for direct and maternal breeding values with the concomitant assignment of genetic groups according to the usual criteria for most recent ancestors without records or more than one collateral descendant. Tables 4 through 6 show the development of the coefficient matrix, absorption of non-parents, and right-hand sides. Although the phenotypic variance is different by $\sigma_{a m}$ for records of progeny with foster dams, the true residual variance is $\sigma_{\mathrm{e}}^{2}$ rather than $\sigma_{\mathrm{e}}^{2}+\sigma_{\mathrm{am}}$. The covariance term is not associated with records of progeny with foster dams unless the foster dam is related to the fostered progeny.

The key differences are that in Table 4 the permanent environmental effect, $\mathrm{p}_{\mathrm{f}}$, is associated with the foster dam rather than the biological mother and that an extra equation is involved for the genetic maternal effect of the foster dam. The genetic maternal equation for the biological mother will drop out in the absorption of a non-parent progeny but it will not drop out for a parent. Essentially what Table 4 shows is that the least squares coefficients of 1 that would have

TABLE 4. CONTRIBUTIONS TO COEFFICIENT MATRIX AND RIGHT-HAND-SIDE VECTOR ASSOCIATED WITH A NON-PARENT, i, THAT HAS SIRE (OR PROXY), s, BIOLOGICAL DAM, j, FOSTER DAM, f, AND RECORD $y_{i}$, CONTAINING FIXED EFFECT, $\beta_{k}$. FOSTER DAM OF SAME BREED IS ASSUMED UNRELATED TO SIRE AND BIOLOGICAL DAM OF FOSTERED PROGENY

\begin{tabular}{|c|c|c|c|c|c|c|c|c|c|c|}
\hline \multirow{2}{*}{$\begin{array}{l}\text { Equation } \\
\text { (row) }\end{array}$} & \multicolumn{9}{|c|}{ Column } & \multirow{2}{*}{$\begin{array}{c}\text { Right } \\
\text { hand } \\
\text { side }\end{array}$} \\
\hline & $a_{1}^{*}$ & $\mathrm{~m}_{\mathrm{i}}^{*}$ & $\beta_{\mathrm{k}}$ & $\mathrm{p}_{\mathrm{f}}$ & $a_{3}^{*}$ & $\mathrm{~m}_{\mathrm{s}}^{*}$ & $\mathbf{a}_{j}^{*}$ & $\mathrm{~m}_{\mathrm{j}}^{*}$ & $\mathrm{~m}_{\mathrm{i}}^{*}$ & \\
\hline$a_{i}^{*}$ & $1+D \alpha$ & $\mathrm{D} \lambda$ & 1 & 1 & $-\mathrm{D} \alpha / 2$ & $-\mathrm{D} \lambda / 2$ & ${ }^{-} \mathrm{D} \alpha / 2$ & $-\mathrm{D} \lambda / 2$ & 1 & $y_{i}$ \\
\hline $\mathrm{m}_{\mathrm{i}}^{*}$ & $\mathrm{D} \lambda$ & $\mathrm{D} \gamma$ & 0 & 0 & $\mathrm{D} \lambda / 2$ & $\mathrm{D} \gamma / 2$ & $-\mathrm{D} \lambda / 2$ & $-\mathrm{D} \gamma / 2$ & 0 & 0 \\
\hline$\beta_{k}$ & 1 & 0 & 1 & 1 & 0 & 0 & 0 & 0 & 1 & $y_{i}$ \\
\hline $\mathbf{p}_{\mathrm{l}}$ & 1 & 0 & 1 & 1 & 0 & 0 & 0 & 0 & 1 & $y_{i}$ \\
\hline$a_{s}^{*}$ & $\mathrm{D} \alpha / 2$ & $\cdots \mathrm{D} \lambda / 2$ & 0 & 0 & $\mathrm{D} \alpha / 4$ & $\mathrm{D} \lambda / 4$ & $\mathrm{D} \alpha / 4$ & $\mathrm{D} \lambda / 4$ & 0 & 0 \\
\hline $\mathrm{m}_{s}^{*}$ & $\mathrm{D} \lambda / 2$ & $\cdots \mathrm{D} \gamma / 2$ & 0 & 0 & $\mathrm{D} \lambda / 4$ & $\mathrm{D}_{\gamma / 4}$ & $\mathrm{D} \lambda / 4$ & $\mathrm{D}_{\gamma / 4}$ & 0 & 0 \\
\hline$a_{j}^{*}$ & $\mathrm{D} \alpha / 2$ & $\mathrm{D} \lambda / 2$ & 0 & 0 & $\mathrm{D} \alpha / 4$ & $\mathrm{D} \lambda / 4$ & $\mathrm{D} \alpha / 4$ & $\mathrm{D} \lambda / 4$ & 0 & 0 \\
\hline $\mathrm{m}_{\mathrm{j}}^{*}$ & $-D \lambda / 2$ & $-D_{\gamma} / 2$ & 0 & 0 & $\mathrm{D} \lambda / 4$ & $D_{\gamma / 4}$ & $\mathrm{D} \lambda / 4$ & $D_{\gamma / 4}$ & 0 & 0 \\
\hline $\mathrm{m}_{1}^{*}$ & 1 & 0 & 1 & 1 & 0 & 0 & 0 & 0 & 1 & $y_{i}$ \\
\hline
\end{tabular}


TABLE 5. ELEMENTS, AFTER SIMPLIFICATION, CONTRIBUTED TO COEFFICIENT MATRIX AND RIGHT-HAND-SIDE VECTOR RESULTING FROM ABSORPTION OF EQUATIONS FOR NON-PARENT, i, THAT HAS SIRE (OR PROXY), s, BIOLOGICAL DAM, j, FOSTER DAM, f, AND RECORD, $y$, CONTAINING FIXED EFFECT, $\beta_{k}$. FOSTER DAM IS OF SAME BREED.

\begin{tabular}{|c|c|c|c|c|c|c|}
\hline \multirow{2}{*}{$\begin{array}{l}\text { Equation } \\
\text { (row) }\end{array}$} & \multicolumn{5}{|c|}{ Column } & \multirow{2}{*}{$\begin{array}{l}\text { Right-hand } \\
\text { side }\end{array}$} \\
\hline & $\beta_{\mathrm{k}}$ & $\mathrm{p}_{\mathrm{i}}$ & $a_{\mathrm{s}}^{*}$ & $a_{j}^{*}$ & $\mathrm{~m}_{\mathrm{f}}^{*}$ & \\
\hline$\beta_{\mathrm{k}}$ & \multirow[t]{2}{*}{$\phi_{0}$} & $\phi_{0}$ & $\phi_{0} / 2$ & $\phi_{0} / 2$ & $\phi_{0}$ & $\phi_{0} y_{i}$ \\
\hline$p_{f}$ & & $\phi_{0}$ & $\phi_{0} / 2$ & $\phi_{0} / 2$ & $\phi_{0}$ & $\phi_{0} y_{i}$ \\
\hline$a_{s}^{*}$ & \multirow{3}{*}{ Symmetric } & & $\phi_{0} / 4$ & $\phi_{0} / 4$ & $\phi_{0} / 2$ & $.5 \phi_{0} y_{i}$ \\
\hline$a_{j}^{*}$ & & & & $\phi_{0} / 4$ & $\phi_{0} 2$ & $.5 \phi_{0} \mathrm{y}_{\mathrm{i}}$ \\
\hline$m_{i}^{*}$ & & & & & $\phi_{11}$ & $\phi_{0} y_{i}$ \\
\hline
\end{tabular}

TABLE 6. ELEMENTS OF COEFFICIENT MATRIX AND RIGHT-HAND-SIDE VECTOR ASSOCIATED WITH A RECORD, $y_{i}$, OF PARENT, $i$, WITH SIRE (OR PROXY GROUP), s, WITH BIOLOGICAL DAM, j, AND FOSTER DAM, f (FOSTER DAM IS OF SAME BREED)

\begin{tabular}{|c|c|c|c|c|c|c|c|c|c|c|}
\hline \multirow{2}{*}{$\begin{array}{l}\text { Equation } \\
\text { (row) }\end{array}$} & \multicolumn{9}{|c|}{ Column } & \multirow{2}{*}{$\begin{array}{l}\text { Right- } \\
\text { hand } \\
\text { side }\end{array}$} \\
\hline & $\beta_{\mathrm{k}}$ & $\mathrm{p}_{\mathrm{r}}$ & $a_{i}^{*}$ & $\mathrm{~m}_{\mathrm{i}}^{*}$ & $a_{s}^{*}$ & $\mathrm{~m}_{\mathrm{s}}^{*}$ & $a_{j}^{*}$ & $\mathrm{~m}_{\mathrm{j}}^{*}$ & $\mathrm{~m}_{i}^{*}$ & \\
\hline$\beta_{k}$ & 1 & 1 & 1 & & & & & 0 & 1 & $y_{i}$ \\
\hline $\mathrm{p}_{f}$ & 1 & 1 & 1 & & & & & 0 & 1 & $y_{i}$ \\
\hline $\mathrm{a}_{j}^{*}$ & 1 & 1 & $1+\mathrm{D} \alpha$ & $\mathrm{D} \lambda$ & $\mathrm{D} \alpha / 2$ & $-D \lambda / 2$ & $\mathrm{D} \boldsymbol{\alpha}_{2} 2$ & $D \lambda / 2$ & 0 & $\begin{array}{l}y_{1} \\
y_{i}\end{array}$ \\
\hline $\mathrm{m}^{*}$ & & & $\mathrm{D} \lambda$ & $\mathrm{D} \gamma$ & $-\mathrm{D} \lambda / 2$ & $\mathrm{D} \gamma / 2$ & $-\mathrm{D} \lambda / 2$ & $\mathrm{D} \gamma: 2$ & 0 & 0 \\
\hline$a^{*}$ & & & $-\mathrm{D} \alpha / 2$ & $\mathrm{D} \lambda: 2$ & $\mathrm{D} \alpha 4$ & $\mathrm{DN} / 4$ & $\mathrm{D} \alpha: 4$ & $\mathrm{D} \lambda / 4$ & 0 & 0 \\
\hline $\mathrm{m}_{\mathrm{s}}^{*}$ & & & $\mathrm{D} \lambda / 2$ & $-D \gamma: 2$ & $\mathrm{D} \lambda \mathrm{4}$ & D $\gamma 4$ & $\mathrm{D} \lambda / 4$ & D $\gamma / 4$ & 0 & 0 \\
\hline$a_{i}^{*}$ & & & $\mathrm{D} \alpha / 2$ & $-\mathrm{D} \lambda 2$ & $\mathrm{D} \alpha / 4$ & $\mathrm{D} \lambda / 4$ & $\mathrm{D} \alpha_{4} 4$ & $\mathrm{D} \lambda / 4$ & 0 & 0 \\
\hline $\mathrm{m}^{*}$ & 0 & 0 & $D \lambda 2$ & D $\gamma 2$ & $\mathrm{D} \lambda \mathrm{A}$ & $\mathrm{D} \gamma / 4$ & $D \lambda 4$ & $\mathrm{D} \gamma / 4$ & 0 & 0 \\
\hline $\mathrm{m}_{\Gamma}^{*}$ & 1 & I & 0 & 0 & 0 & 0 & 0 & 0 & I & $y_{i}$ \\
\hline
\end{tabular}

been assigned to the maternal equation and associated coefficients are assigned to the foster dam as shown, and the progeny record goes to the right-hand side for the foster dam rather than biological mother. Also, the permanent environmental effect is that of the foster dam rather than the biological mother. Table 5 shows the coefficients contributed by the absorption of the equations for direct and maternal breeding values of a non-parent. Note that the biological dam and sire are treated exactly the same, so that with algebraic simplification the coefficients and equations for the maternal breeding values of both the sire and dam drop out in the absorption to the RAM-Q-P-W form. As expected, the equation and coefficients associated with the maternal breeding value of the foster dam do not drop out.

Table 6 lists the contributions to the coefficient matrix and right-hand sides for a parent that had a foster dam of the same breed. Again note that $p_{f}$ is included rather than $p_{j}$ and that $m_{i}^{*}$ receives the least squares "one"s" rather than $\mathrm{m}_{\mathrm{j}}^{*}$. Also, the progeny record goes to the right-hand side for the permanent environmental and maternal breeding value equations of the foster dam rather than the biological dam.

If a foster dam never contributes maternal effects to more than one progeny (biological or fostered), then the $p_{f}$ equation could be absorbed as indicated in the previous section. Carrying the extra equations, however, might be easier than checking to make sure that only one progeny had maternal effects from a foster dam. The equations for the maternal effect of a foster dam might be as easy to absorb as the permanent environmental effect based on the similarities shown in Tables 5 and 6 . However, the equation for maternal breeding value of the foster dam will be tied to her parents through $\mathrm{W}$, which will need to be calculated before solving the whole set of equations. 


\section{Foster Dams of Many Breeds with Relationships Considered Within Breed}

The most daunting alternative is to consider many breeds of foster dams and relationships among foster dams of the same breed. For this case, the assumption will be made that only foster dams of the same breed as the breed for which evaluations are being made will also have biological progeny. The preceding section discusses how to handle foster dams of the same breed. If foster dams of other breeds are considered for computational reasons to be unrelated, then procedures described either for the fixed breed-period group or for the nested, unrelated, foster dam within breed-period group models could be used along with procedures for utilizing relationships for foster dams of the breed being evaluated.

A more general approach is to consider numerator relationships within the breed groups of foster dams and also to allow foster dams to act as foster dams more than once. Not only breeding values for maternal effects of the foster dams could be predicted, but also breeding values of direct effects through the genetic correlation between direct and maternal effects. The purpose, however, of accounting for the effect of the foster dam is to improve evaluations for animals of the donor breed. Therefore, the direct effects for foster dams of other breeds will not be included in the model. In fact, including those direct values without their performance records would not add any information. Foster dams would provide a way of tying together evaluations of breeds, although the ties, through foster dams, would be weak and susceptible to choice of foster dams and management of foster dams. This discussion will be limited to evaluations for a single breed with some foster dams contributed by other breeds. For illustration, only one other breed of foster dams will be considered. The same rules would apply to other breeds.

For records of progeny with foster dams of the same breed, the rules for setting up the equations given in the previous section apply (Tables 4 through 6 ).

The Q-P-W equations with two breeds of foster dams (donor breed and one recipient breed) are:

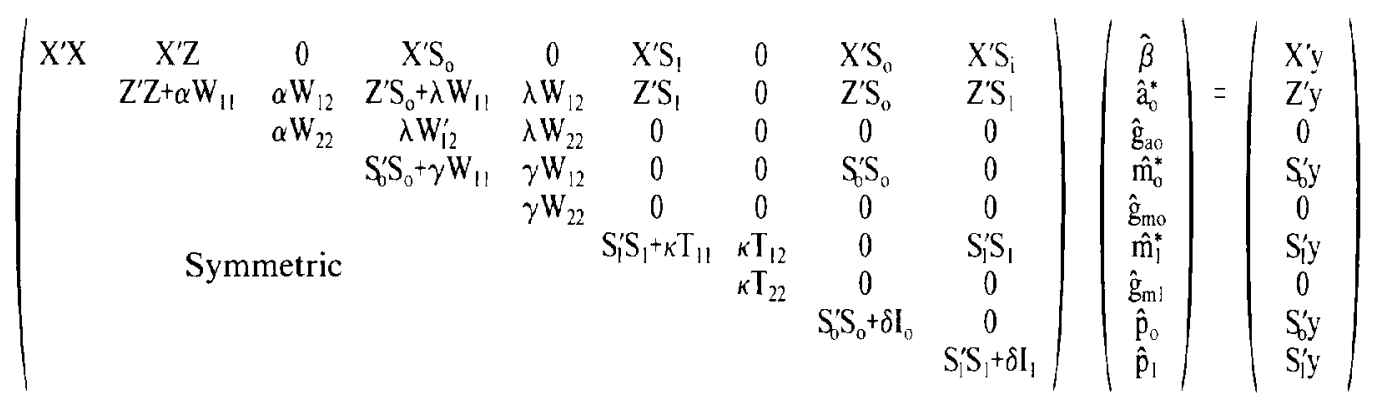

where

$y$ is the vector of records with zero for animals without records;

$X$ is a matrix associating elements of fixed effects in $\beta$ with $y$;

$Z$ is a matrix associating breeding values for direct effects in $a_{0}^{*}=a_{0}+Q_{0} g_{a o}$ with $y$ (for animals in $\mathrm{a}_{\mathrm{o}}$ without records, the corresponding rows of $\mathrm{Z}$ will be null);

$S_{0}$ is a matrix associating maternal breeding values and nongenetic maternal effects of mothers of the same breed $\left(m_{0}^{*}=m_{o}+Q_{o} g_{m o}\right.$ and $\left.p_{o}\right)$ with $y$;

$S_{1}$ is a matrix associating maternal breeding values and nongenetic maternal effects for foster dams of breed $1\left(m_{1}^{*}=m_{1}+Q_{1} g_{m 1}\right.$ and $\left.p_{1}\right)$ with records of breed $o, y$;

$\mathrm{g}_{\mathrm{ao}}$ is the vector of direct effects of genetic groups for breed o;

$\mathrm{g}_{\mathrm{mo}}$ is the vector of maternal effects of genetic groups for breed $\mathrm{o}$;

$\mathrm{g}_{\mathrm{m}}$ is the vector of maternal effects of genetic groups for breed 1 ;

$$
W=\left(\begin{array}{ll}
W_{11} & W_{12} \\
W_{12}^{\prime} & W_{22}
\end{array}\right)
$$

is the matrix of coefficients for breed o based on Westell's rules that incorporate $A^{-1}$ and the relationships of base animals and their genetic groups to animals included in $\mathbf{a}_{0}$; 
$\mathrm{T}$ is similarly the matrix of coefficients for breed 1 based on Westell's rules;

$$
\begin{aligned}
\left(\begin{array}{ll}
\alpha & \lambda \\
\lambda & \gamma
\end{array}\right)= & \sigma_{\mathrm{e}}^{2}\left(\begin{array}{ll}
\sigma_{\mathrm{a}}^{2} & \sigma_{\mathrm{am}} \\
\sigma_{\mathrm{am}} & \sigma_{\mathrm{m}}^{2}
\end{array}\right)^{-1} \text { with } \\
\sigma_{\mathrm{e}}^{2}= & \text { residual variance, } \\
\sigma_{\mathrm{a}}^{2}= & \text { variance of additive direct effects, } \\
\sigma_{\mathrm{m}}^{2}= & \text { variance of additive maternal effects. } \\
\sigma_{\mathrm{am}}= & \text { covariance of additive direct and maternal effects; } \\
\kappa= & \sigma_{\mathrm{e}}^{2} / \sigma_{\mathrm{m}}^{2} ; \\
\delta= & \sigma_{\mathrm{e}}^{2} / \sigma_{\mathrm{p}}^{2} ; \text { and } \\
\mathrm{I}_{\mathrm{o}}, \mathrm{I}_{\mathrm{I}} & \text { are square matrices of order the number of animals of breeds o and } 1 \text { included in } \\
& \mathrm{m}_{\mathrm{o}}^{*} \text { and } \mathrm{m}_{1}^{*} ; \text { with zeros on the off-diagonals and zero or one on the diagonals. } \\
& \text { When animals in } \mathrm{m}_{\mathrm{o}}^{*} \text { and } \mathrm{m}_{1}^{*} \text { are not foster or biological dams of animals with } \\
& \text { records the corresponding diagonals of } \mathrm{I}_{\mathrm{o}} \text { and } \mathrm{I}_{1} \text { are zero. Similarly some } \\
& \text { diagonals of } \mathrm{S}_{\mathrm{o}}^{\prime} \mathrm{S}_{\mathrm{o}} \text { and } \mathrm{S}_{\mathrm{l}}^{\prime} \mathrm{S}_{1} \text { will be zero because the corresponding rows of } \mathrm{S}_{\mathrm{o}} \text { and } \\
& \mathrm{S}_{1} \text { will contain only zeroes for animals that are not dams but are included in } \mathrm{m}_{\mathrm{o}}^{*} \\
& \text { and } \mathrm{m}_{1}^{*} \text { to create relationships. }
\end{aligned}
$$

Additional breeds of foster dams will involve additional $X^{\prime} S_{i}, Z^{\prime} S_{i}, S_{i}^{\prime} S_{i}, S_{i}^{\prime} S y, \hat{m}_{i}^{*}, \hat{p}_{i}$ and $\hat{\mathrm{g}}_{\mathrm{mi}}$ terms, as well as the corresponding Westell coefficients for those breeds. If the breed-group of foster dam changes the residual variance but does not change the proportions of the maternal genetic and maternal nongenetic variances to phenotypic variance, then adjustment for differences in variance would consist of using terms such as $\sigma_{\mathrm{e}_{1}}^{2} / \sigma_{\mathrm{e}_{\mathrm{e}}}^{2}$ rather than one's for the contributions to the least squares and right-hand sides when the foster dam is of breed $\mathrm{i}$.

The rules for setting up the coefficient matrix are of two kinds:1) those with same breed of dam, foster dam or biological dam, and 2) those with a different breed of foster dam.

\section{Foster Dam of the Same Breed}

The rules for foster dams of the same breed were summarized in Table 4 (non-parents) and Table 6 (parents). The rules for the RAM-Q-P-W form are in Table 5 (non-parents) and are the same for parents (Table 6) as for the Q-P-W form. Tables 1, 2 and 3 of Van Vleck (1990b) summarize the rules for the biological dam providing maternal effects. Recall that foster dams of the same breed are added to the $\mathrm{a}_{0}^{*}$ and $\mathrm{m}_{0}^{*}$ vectors and must be assigned to genetic groups as for other animals. If a foster dam is also a biological dam, the rules for the coefficients for her two kinds of progeny will be slightly different (Tables 1 and 2 this paper vs tables 1 and 2 of Van Vleck, 1990b).

\section{Foster Dam of Another Breed}

Table 7 lists the contributions to the coefficient matrix and right-hand sides associated with a record of a non-parent that had a foster dam of another breed. The contributions are similar to those in Table 4 (foster dam of same breed) except that $p_{[}$and $m_{f}^{*}$ are of another breed and that because the residual variance may be $\sigma_{\mathrm{e}_{n}}^{2}, r=\sigma_{\mathrm{e}_{\mathrm{n}}}^{2} / \sigma_{\mathrm{e}_{\mathrm{h}}}^{2}$ will replace the one's and ry $\mathrm{y}_{\mathrm{i}}$ will replace $\mathrm{y}_{\mathrm{i}}$.

Rules for setting up the coefficient matrix and right-hand sides resulting from the absorption of a non-parent with a foster dam of another breed are in Table 8 . The $\phi$ 's may follow the form of those in Table 2 if the absorption involves

$$
\left(\begin{array}{cc}
\mathrm{r}+\mathrm{D} \alpha & \mathrm{D} \lambda \\
\mathrm{D} \lambda & \mathrm{D} \gamma
\end{array}\right)^{-1}=\left(\begin{array}{ll}
\alpha^{+} & \lambda^{+} \\
\lambda^{+} & \gamma^{+}
\end{array}\right) \text {rather than }\left(\begin{array}{cc}
1+\mathrm{D} \alpha & \mathrm{D} \lambda \\
\mathrm{D} \lambda & \mathrm{D} \gamma
\end{array}\right)^{-1}
$$

The coefficients simplify as in Table 2 to those shown in Table 9. 
TABLE 7. CONTRIBUTIONS TO COEFFICIENT MATRIX AND RIGHT-HAND-SIDE VECTOR ASSOCIATED WITH A NON-PARENT, i, THAT HAS SIRE (OR PROXY), s, BIOLOGICAL DAM, j. FOSTER DAM, $f$, OF ANOTHER BREED, AND RECORD $y_{i}$, CONTAINING FIXED EFFECT, $\beta_{k}{ }^{a}$.

\begin{tabular}{|c|c|c|c|c|c|c|c|c|c|c|}
\hline \multirow{2}{*}{$\begin{array}{l}\text { Equation } \\
\text { (row) }\end{array}$} & \multicolumn{9}{|c|}{ Column } & \multirow{2}{*}{$\begin{array}{c}\text { Right- } \\
\text { hand } \\
\text { side }\end{array}$} \\
\hline & $a_{i}^{*}$ & $\mathrm{~m}_{\mathrm{i}}^{*}$ & $\beta_{\mathrm{k}}$ & $p_{\mathrm{f}}$ & $a_{\mathrm{s}}^{*}$ & $\mathrm{~m}_{\mathrm{s}}^{*}$ & $a_{j}^{*}$ & $\mathrm{~m}_{\mathrm{j}}^{*}$ & $\mathrm{~m}_{\mathrm{i}}^{*}$ & \\
\hline$a_{i}^{*}$ & $\mathrm{r}+\mathrm{D} \alpha$ & $\mathrm{D} \lambda$ & $r$ & $r$ & $\mathrm{D} \alpha / 2$ & $-\mathrm{D} \lambda / 2$ & $\mathrm{D} \alpha / 2$ & $-\mathrm{D} \lambda / 2$ & $r$ & $r y_{i}$ \\
\hline $\mathrm{m}_{\mathrm{i}}^{*}$ & $\mathrm{D} \lambda$ & $\mathrm{D} \gamma$ & 0 & 0 & $\mathrm{D} \lambda / 2$ & $-\mathrm{D} \gamma / 2$ & $-\mathrm{D} \lambda / 2$ & $\cdots \mathrm{D} \gamma / 2$ & 0 & 0 \\
\hline$\beta_{\mathrm{k}}$ & $r$ & 0 & $r$ & $r$ & 0 & 0 & 0 & 0 & $\mathrm{r}$ & $r y_{i}$ \\
\hline $\mathrm{p}_{\mathrm{f}}$ & $r$ & 0 & $r$ & $r$ & 0 & 0 & 0 & 0 & $r$ & $r y_{i}$ \\
\hline$a_{s}^{*}$ & $\mathrm{D} \alpha: 2$ & $\mathrm{D} \lambda / 2$ & 0 & 0 & $\mathrm{D} \alpha / 4$ & $\mathrm{D} \lambda / 4$ & $\mathrm{D} \alpha / 4$ & $\mathrm{DN} / 4$ & 0 & 0 \\
\hline $\mathrm{m}_{\mathrm{s}}^{*}$ & $-\mathrm{D} \lambda / 2$ & $\mathrm{D} \gamma: 2$ & 0 & 0 & $\mathrm{D} \lambda / 4$ & $\mathrm{D} \gamma / 4$ & $\mathrm{D} \lambda / 4$ & $\mathrm{D} \gamma / 4$ & 0 & 0 \\
\hline$a_{j}^{*}$ & $\mathrm{D} \alpha / 2$ & $-\mathrm{D} \lambda / 2$ & 0 & 0 & $\mathrm{D} \alpha / 4$ & $\mathrm{D} \lambda / 4$ & $\mathrm{D} \alpha / 4$ & $\mathrm{D} \lambda / 4$ & 0 & 0 \\
\hline $\mathrm{m}_{\mathrm{j}}^{*}$ & $\mathrm{DN}: 2$ & $-\mathrm{D} \gamma / 2$ & 0 & 0 & $\mathrm{D} \lambda / 4$ & $\mathrm{D} \gamma / 4$ & $\mathrm{D} \lambda / 4$ & $\mathrm{D} \gamma / 4$ & 0 & 0 \\
\hline $\mathrm{m}_{\mathrm{f}}^{*}$ & $r$ & 0 & $r$ & $r$ & 0 & 0 & 0 & 0 & $r$ & $r y_{i}$ \\
\hline
\end{tabular}

${ }_{\mathrm{a}} \mathbf{\square} \sigma_{\mathrm{e},}^{2} / \sigma_{\mathrm{e}_{\mathrm{b}}}^{2}$ where $\sigma_{\mathrm{e}, \text { in }}^{2}$ is residual variance for records of progeny of donor breed, $o$, and $\sigma_{\mathrm{e}_{\mathrm{b}}}^{2}$ is residual variance for records of progeny with foster dam of breed $b$.

TABLE 8. ELEMENTS, AFTER SIMPLIFICATION, CONTRIBUTED TO COEFFICIENT MATRIX AND RIGHT-HAND-SIDE VECTOR RESULTING FROM ABSOR PTION OF EQUATIONS FOR NON-PARENT, i, THAT HAS SIRE (OR PROXY), s, BIOLOGICAL DAM, j, FOSTER DAM, f, OF ANOTHER BREED AND RECORD, $y_{i}$, CONTAINING FIXED EFFECT, $\beta_{k}$.

\begin{tabular}{|c|c|c|c|c|c|c|}
\hline \multirow{2}{*}{$\begin{array}{l}\text { Equation } \\
\text { (row) }\end{array}$} & \multicolumn{5}{|c|}{ Column } & \multirow{2}{*}{$\begin{array}{l}\text { Right-hand } \\
\text { side }\end{array}$} \\
\hline & $\beta_{\mathrm{k}}$ & $\mathrm{p}_{\mathrm{f}}$ & $a_{s}^{*}$ & $a_{j}^{*}$ & $\mathrm{~m}_{\mathrm{i}}^{*}$ & \\
\hline$\overline{\beta_{k}}$ & \multirow{5}{*}{$\begin{array}{c}\phi_{0}^{-} \\
\text {Symmetric }\end{array}$} & $\phi_{0}^{+}$ & $\overline{\phi_{0 / 2}^{+} / 2}$ & $\phi_{0}^{+} / 2$ & $\overline{\phi_{0}^{+}}$ & $\overline{\phi_{0}^{+} \mathrm{y}_{\mathrm{i}}}$ \\
\hline$p_{i}$ & & \multirow[t]{4}{*}{$\phi_{0}^{+}$} & $\phi_{0}^{+} / 2$ & $\phi_{0}^{+} / 2$ & $\phi_{0}^{+}$ & $\phi_{0}^{+} \mathrm{y}_{i}$ \\
\hline$a_{4}^{*}$ & & & $\phi_{0}^{*} / 4$ & $\phi_{0}^{+} 4$ & $\phi_{0}^{+} / 2$ & $.5 \phi_{i j}^{+} y_{i}$ \\
\hline $\mathbf{a}_{\mathrm{j}}^{*}$ & & & & $\phi_{0}^{+}, 4$ & $\phi_{0}^{+} / 2$ & $.5 \phi_{i}^{+} y_{i}$ \\
\hline $\mathrm{m}_{1}^{\mathrm{x}}$ & & & & & $\phi_{0}^{+}$ & $\phi_{1}^{+} y_{i}$ \\
\hline
\end{tabular}

Note that if $r=1$, replace $\phi$ with $\phi$.

TABIE 9. ELEMENTS OF COEFFICIENT MATRIX AND RIGHT-HAND-SIDE VECTOR ASSOCIATED WITH A PARENT, i, THAT HAS SIRE (OR PROXY), s, BIOLOGICAL DAM, j, FOSTER DAM, $f$, OF ANOTHER BREED, AND RECORD $y_{i}$, CONTAINING FIXED EFFECT, $\beta_{k}$

\begin{tabular}{|c|c|c|c|c|c|c|c|c|c|c|}
\hline \multirow{2}{*}{$\begin{array}{c}\text { Equation } \\
\text { (row) }\end{array}$} & \multicolumn{9}{|c|}{ Column } & \multirow{2}{*}{$\begin{array}{l}\text { Right- } \\
\text { hand } \\
\text { side }\end{array}$} \\
\hline & $\beta_{\mathrm{k}}$ & $\mathbf{p}_{1}$ & $a_{i}^{*}$ & $\mathrm{~m}_{\mathrm{i}}^{*}$ & $a_{s}^{x}$ & $\mathrm{~m}_{\mathrm{s}}^{*}$ & $a_{j}^{*}$ & $\mathrm{~m}_{\mathrm{j}}^{*}$ & $\mathrm{~m}^{*}$ & \\
\hline$\beta_{k}$ & $r$ & $r$ & I & & & & & & $r$ & $r y_{i}$ \\
\hline$p_{1}$ & $r$ & $r$ & r & & & & & & $r$ & $r y_{i}$ \\
\hline $\mathrm{a}_{\mathrm{i}}^{x}$ & $r$ & $r$ & $\mathrm{r}+\mathrm{D} \alpha$ & $D \lambda$ & $\mathrm{D} \alpha 2$ & $\mathrm{DA} 2$ & $\mathrm{D} \alpha / 2$ & $-\mathrm{D} \lambda / 2$ & $r$ & $r y_{i}$ \\
\hline $\mathrm{m}_{\mathrm{i}}^{*}$ & & & $\mathrm{D} \lambda$ & $D \gamma$ & $-D \lambda 2$ & Dr: 2 & $\mathrm{DN} 2$ & $-\mathrm{D} \gamma: 2$ & 0 & 0 \\
\hline$a_{4}^{*}$ & & & $D \alpha: 2$ & $\mathrm{DN}: 2$ & $D \alpha 4$ & $D \lambda_{i} 4$ & $\mathrm{D} \alpha / 4$ & $\mathrm{D} \lambda / 4$ & 0 & 0 \\
\hline $\mathrm{m}^{*}$ & & & $-D \lambda: 2$ & $\mathrm{D} \gamma: 2$ & $D \lambda / 4$ & $\mathrm{D}_{\gamma / 4}$ & $\mathrm{D} \lambda / 4$ & $\mathrm{D} \gamma / 4$ & 0 & 0 \\
\hline $\mathrm{a}_{\mathrm{j}}^{*}$ & & & $\mathrm{D} \alpha / 2$ & $\mathrm{D} \lambda 2$ & $\mathrm{D} \alpha / 4$ & $\mathrm{D} \lambda / 4$ & $\mathrm{D} \alpha / 4$ & $\mathrm{D} \lambda / 4$ & 0 & 0 \\
\hline $\mathrm{m}_{\mathrm{j}}^{*}$ & & & $\mathrm{D} \lambda: 2$ & $-\mathrm{D} \gamma: 2$ & $D \lambda / 4$ & Drit & $\mathrm{D} \lambda / 4$ & $\mathrm{D} \gamma / 4$ & 0 & 0 \\
\hline $\mathrm{m}_{i}^{*}$ & $r$ & $r$ & $r$ & 0 & 0 & 0 & 0 & 0 & $r$ & ry $y_{i}$ \\
\hline
\end{tabular}

$r=\sigma_{\mathrm{c}}^{2}, \sigma_{\mathrm{e}_{\mathrm{s}}}^{2}$ where $\sigma_{\mathrm{t}}^{2}$ is residual variance for records of progeny of donor breed, $\mathbf{o}$, and $\sigma_{\mathrm{e}_{\mathrm{h}}}^{2}$ is residual variance for records of progeny with foster dam of breed $b$.

Table 9 shows the contributions associated with the record of a parent that had a foster dam of another breed.

One step remains in setting up either the RAM-Q-P-W or Q-P-W equations. All animals included in the $m_{1}^{*}$ vector, either those that are foster dams or those that relate foster dams to one another, such as sires, grandsires, and dams, will contribute coefficients based on $\mathrm{T}$, the 
TABLE 10. CONTRIBUTIONS TO COEFFICIENT MATRIX OF A FOSTER DAM, $\mathrm{f}$, OF ANOTHER BREED THROUGH RELATIONSHIPS TO HER SIRE (OR PROXY), $f_{s}$, AND DAM (OR PROXY), $f_{d}{ }^{a}$

\begin{tabular}{|c|c|c|c|}
\hline \multirow{2}{*}{$\begin{array}{l}\text { Equation } \\
\text { (row) }\end{array}$} & \multicolumn{3}{|c|}{ Column } \\
\hline & $\mathrm{m}_{\mathrm{i}}^{*}$ & $\mathrm{~m}_{i}^{*}$ & $\mathrm{~m}_{\mathrm{f}}^{*}$ \\
\hline $\begin{array}{l}\mathrm{m}_{\mathrm{i}}^{*} \\
\mathrm{~m}_{\mathrm{f}}^{*} \\
\mathrm{~m}_{\mathrm{i}_{4}}^{*}\end{array}$ & $\begin{array}{c}D_{\kappa} \\
-D \kappa: 2 \\
-D \kappa: 2\end{array}$ & $\begin{array}{l}D \kappa / 2 \\
D \kappa / 4 \\
D \kappa\end{array}$ & $\begin{array}{l}\mathrm{D}_{\kappa / 2} \\
\mathrm{D}_{\kappa / 4} \\
\mathrm{D}_{\kappa / 4}\end{array}$ \\
\hline
\end{tabular}

$a_{K}=\sigma_{t}^{2} / \alpha_{m}^{2}$

coefficients resulting from Westell's rules applied to the within-breed populations of foster dams, relatives, and genetic groups. These coefficients do not involve any right-hand sides and are shown in Table 10. Because additive direct breeding values of animals of the breed of foster dam are not in the equations, the variance ratio associated with $\mathrm{T}$ (the Westell coefficients) is $\sigma_{\mathrm{e}}^{2} / \sigma_{\mathrm{m}}^{2}=$ $\kappa$.

Before solving the RAM-Q-P-W or Q-P-W equations, $\delta=\sigma_{\mathrm{e}}^{2} / \sigma_{\mathrm{p}}^{2}$ must be added to the diagonals of all the equations for nongenetic maternal effects for all breeds.

\section{Conclusions}

All the alternatives discussed here that adjust for the maternal effect of the dam (biological or foster) are relatively easy to apply. The easiest method is to group the foster dams by breed-period and to fit a model including fixed breed-period effects. If foster dams are assumed to be nested within a breed-period group, have only one foster progeny, and be unrelated, those effects can be absorbed into the other equations nearly as readily as setting up the equations without the random foster dam effects. In either case, the number of equations is increased only by the number of breed-period groups of foster dams. Such a procedure may provide adequate adjustment for foster dam effects.

Proper adjustment for ages of foster dams of different breeds may be quite important. Some adjustment for change in variance, either due to the breed of foster dam or because only a fixed effect of foster dam group is fit, may not be very important. Probably of more importance will be whether foster dams of other breeds are selected in some way that differentially enhances or detracts from performance of fostered progeny in different herds or contemporary groups. Making the breed-period groups into breed-herd-period groups seems to be an attractive option but may lead to complete confounding with contemporary group effects.

When the foster dam is of the same breed, the evaluation procedure is little changed from the usual one with the biological dam contributing maternal effects. The most important consideration may be that listed above: whether the foster dams are selected in some way differentially from herd to herd.

Consideration of within-breed relationships among foster dams of another breed also does not seem very computationally demanding. The usual rules for Q-P-W or RAM-Q-P-W equations are easily modified to account for those relationships. Assignment of genetic maternal groups may be arbitrary but may not be a very important decision. How many relatives of the foster dams to include to make the relationships among foster dams meaningful may not seem to be an easy decision to make, but again, having a complete relationship matrix may not be very important. The number of equations would be increased by the number of relatives used in $m_{l}^{*}$ (equations in $p_{1}$ do not have to be formed for the relatives that are not foster dams).

\section{Implications}

Maternal effects are important for many traits. Embryo transfer results in the post-conception maternal effect being provided by a foster or surrogate mother of the same or a different breed. Alternatives to account for foster dam effects that were discussed here can be applied to animal model evaluations relatively easily by modifying slightly the rules for calculating the coefficients 
for mixed-model equations for the animal model or for the reduced animal model. Genetic relationships among foster dams and between foster dams of the same breed and animals with records can be easily incorporated, as can maternal group effects to account for previous selection of animals used as foster dams.

\section{Literature Cited}

Benyshek, L. L., M. H. Johnson, D. E. Little, J. K. Bertrand, and L. A. Kriese. 1988. Application of an animal model in the United States beef cattle industry. In: Proc. Animal Model Workshop. J. Dairy Sci. 71 (Suppl.2):35.

Henderson, C. R. 1977. Best linear unbiased prediction of breeding values not in the model for records. J. Dairy Sci. 60:783.

Quaas, R. L. 1976. Computing the diagonal elements and inverse of a large numerator relationship matrix. Biometrics 32:949.

Quaas, R. L. 1988. Additive genetic model with groups and relationships. J. Dairy Sci. 71:1338.

Quaas, R. L. and E. J. Pollak. 1980. Mixed model methodology for farm and ranch beef cattle testing programs. J. Anim. Sci. 51:1277.

Quaas, R. L. and E. J. Pollak. 1981. Modified equations for sire models with groups. J. Dairy Sci. 64:1868.

Schaeffer, L. R. and B. W. Kennedy. 1989. Effects of embryo transfer in beef cattle on genetic evaluation methodology. J. Anim. Sci. 67:2536.

Van Vleck, L. D. 1990a. Breeding value prediction with maternal genetic groups. J. Anim. Sci. 68:3998.

Van Vleck, L. D. 1990b. Absorption of equations for nonparents for an animal model with maternal effects and genetic groups. J. Anim. Sci. 68:4014.

Westell, R. A. 1984. Simultaneous evaluation of sires and cows for a large population. Ph.D. Dissertation, Cornell Univ., Ithaca, NY.

Westell, R. A., R. L. Quaas and L. D. Van Vleck. 1984. Genetic groups in an animal model. J. Anim. Sci. 59(Suppl.1):175. (Abstr.).

Westell, R. A., R. L. Quaas and L. D. Van Vleck. 1988. Genetic groups in an animal model. J. Dairy Sci. $71: 1310$.

Wiggans, G. R., I. Misztal and L. D. Van Vleck. 1988. Implementation of an animal model for genetic evaluation of dairy cattle in the United States. In: Proc. Animal Model Workshop. J. Dairy Sci. $71:$ (Suppl.2):54. 